\title{
The Effect of Hydration on the Cation- $\pi$ Interaction Between Benzene and Various Cations
}

\author{
VIKASH DHINDHWAL ${ }^{\mathrm{a}}$ and N SATHYAMURTHY ${ }^{\mathrm{a}, \mathrm{b}, *}$ \\ ${ }^{a}$ Department of Chemistry, Indian Institute of Science Education and Research Mohali, \\ SAS Nagar Manauli, Punjab 140 306, India \\ ${ }^{b}$ Department of Chemistry, Indian Institute of Technology Kanpur, Kanpur, Uttar Pradesh 208 016, India \\ e-mail: nsath@iisermohali.ac.in
}

MS received 17 August 2016; accepted 18 August 2016

\begin{abstract}
The effect of hydration on cation- $\pi$ interaction in $M^{q+} B_{m} W_{n}\left(B=\right.$ benzene; $W=$ water; $M^{q+}=$ $\left.\mathrm{Na}^{+}, \mathrm{K}^{+}, \mathrm{Mg}^{2+}, \mathrm{Ca}^{2+}, \mathrm{Al}^{3+}, 0 \leq n, m \leq 4,1 \leq m+n \leq 4\right)$ complexes has been investigated using ab initio quantum chemical methods. Interaction energy values computed at the MP2 level of theory using the 6-31G $(d, p)$ basis set reveal a qualitative trend in the relative affinity of different cations for benzene and water in these complexes. The $\pi$-cloud thickness values for benzene have also been estimated for these systems.
\end{abstract}

Keywords. Cation- $\pi$ interaction; $\pi$-thickness; non-covalent interaction; hydration; alkali and alkaline earth metal cations; benzene.

\section{Introduction}

Non-covalent interactions like hydrogen bond, $\pi-\pi$ stacking interaction, van der Waals interaction, cation$\pi$ interaction, etc., play a vital role in determining the physical and chemical properties of substances. They have been studied extensively to determine the extent of their influence on chemical and biological systems. ${ }^{1-6}$ These interactions are used to design novel materials and synthetic routes for efficient chemical processes. Cation- $\pi$ interactions, being ubiquitous in nature, are known to govern various phenomena like stereoselectivity, size specificity, etc., in chemical and biological processes. ${ }^{7-17}$ Comprehensive reviews of the subject have been written by Ma and Dougherty ${ }^{7}$, Dougherty ${ }^{8}$ and Mahadevi and Sastry. ${ }^{9}$

The strength of the cation $-\pi$ interaction depends on a variety of factors like the nature of the cation, nature of the $\pi$-system, heteroatoms in the $\pi$-system, substituents in the $\pi$-system, solvation, etc. The interaction between cations having a higher charge density and less coordination and arenes $(\pi$-systems) with larger quadrupole moments is stronger due to larger electrostatic interaction. The cations are known to have a preference for binding to a $\pi$-system with a higher $\pi$-electron density and aromaticity. ${ }^{18}$

Solvation of the cation is expected to affect the strength of the cation $-\pi$ interaction significantly. The

*For correspondence

Celebrating 100 years of Lewis Chemical Bond nature of the solvent determines the absolute and relative strengths of the interaction. For a given cation$\pi$ system, the interaction energy decreases with an increase in solvent polarity. ${ }^{19}$ It can be explained in terms of both solvation and coordinate saturation of the cation. The cation $-\pi$ interaction energy decreases with an increase in the solvation of the metal cation. Interestingly, hydration on the no-cation-side of the aromatic ring enhances the cation- $\pi$ interaction. ${ }^{20}$ There seems to be a balance between solvation energy and the cation$\pi$ interaction in many chemical and biological phenomena. Ion-specificity in $\mathrm{K}^{+}$-ion channels seems to arise from cation $-\pi$ interaction. ${ }^{12}$ The specificity is attributed to the sufficiently strong interaction between benzene and $\mathrm{K}^{+}$resulting in partial dehydration of the metal ion. $\mathrm{Na}^{+}$does not have such a strong interaction due to a larger hydration energy. ${ }^{21}$

The present work focuses on the effect of hydration on the cation $-\pi$ interaction between various metal cations $\left(\mathrm{Na}^{+}, \mathrm{K}^{+}, \mathrm{Mg}^{2+}, \mathrm{Ca}^{2+}, \mathrm{Al}^{3+}\right)$ and benzene. It has been carried out by computing the strength of the cation $-\pi$ interaction for different metal cations in the free state and in partially hydrated states with benzene as the $\pi$-system and comparing it with the strength of interaction of the cation with water. Several computational and experimental works ${ }^{21-26}$ have been directed towards studying the interaction of metal cations with benzene but the effect of hydration (solvation) has been studied to a limited extent. Some of them do not discuss the solvent effect, but calculate the cation $-\pi$ interaction between benzene and alkali or alkaline-earth 
metal cations at different levels of theory and basis sets. Amicangelo and Armentrout ${ }^{22}$ determined the absolute binding energy of alkali-metal cations with benzene and benzene dimer using the threshold collision-induced experiments and ab initio quantum calculations at the MP2 level of theory and $6-31 \mathrm{G}^{*}$ and $6-31 \mathrm{G}+{ }^{* *}$ basis sets. Cabarcos et al., ${ }^{21}$ studied the solvation of $\mathrm{Na}^{+}$ and $\mathrm{K}^{+}$by benzene and water using vibrational spectroscopy and proposed a mechanism for the sizeselectivity of the $\mathrm{K}^{+}$-ion channel proteins in terms of cation $-\pi$ interaction. They found that the $\mathrm{K}^{+}$ion could get partly dehydrated from its first solvation shell to bind with an aromatic moiety but the $\mathrm{Na}^{+}$ion preferred to retain the water molecules because of high hydration energy. Reddy et al., ${ }^{23}$ studied the effect of sequential addition of water molecules (1 to 6) on the interaction between alkali and alkaline-earth metal cations and a benzene molecule and found that there was a reduction in the cation $-\pi$ interaction energy and an increase in the cation-benzene distance as the number of water molecules around the cation increased. Nicholas et al. ${ }^{24}$ carried out an ab initio molecular orbital study of the cation- $\pi$ binding between alkali-metal cations and benzene at various levels of theory. Feller et al., ${ }^{25}$ estimated the complete basis set (CBS) limit for the cation $-\pi$ interaction for alkali-metal cation-benzene systems. Mishra et al. ${ }^{26}$ studied the interaction of benzene dimer and trimer with a host of cations at the MP2 level of theory using the $6-31 \mathrm{G}(d, p)$ basis set. They reported the cation $-\pi$ interaction energy values and $\pi$-cloud thickness values. Kolakkandy et al. ${ }^{27}$ have calculated the cation- $\pi$ binding energy values for metal-benzene complexes, $M^{q+} B_{n}$, where $M^{q+}=\mathrm{Na}^{+}$, $\mathrm{Mg}^{2+}, \mathrm{Fe}^{2+}$ and $n=1-3$.

In the present work, the cations under investigation are alkali metal $\left(\mathrm{Na}^{+}, \mathrm{K}^{+}\right)$, alkaline earth $\left(\mathrm{Mg}^{2+}, \mathrm{Ca}^{2+}\right)$ metal cations and $\mathrm{Al}^{3+}$. The total number of molecules around these cations is varied from one to four with all possible combinations of benzene and water. The aim of the study is to determine the change in the magnitude of the interaction energy with a change in the number of water and benzene molecules around the metal cation, thereby assessing the effect of hydration on cation $-\pi$ interaction.

\section{Methodology}

Cation- $\pi$ interaction energy $(\Delta E)$ values for the $M^{q+} B_{n} W_{m}$ system were calculated using the supermolecule method:

$\Delta E=E\left(M^{q+} B_{n} W_{m}\right)-\left[E\left(M^{q+}\right)+n E(B)+m E(W)\right]$.
The $\pi$-cloud thickness $(\rho)$ value for benzene was estimated by subtracting the ionic radius $(r)$ of the cation from the centre-of-mass separation $(R)$ between the cation and the centre of the benzene ring in the optimized geometry:

$$
\rho=R-r .
$$

Charge density $(\varepsilon)$ values for the cations were calculated by dividing the total electronic charge by the ionic volume:

$$
\varepsilon=\frac{q \times \mathrm{e}}{\frac{4}{3} \pi r^{3}},
$$

where ' $\mathrm{e}$ ' is the electronic charge.

\subsection{Computational details}

Gaussian 09 suite of programs ${ }^{28}$ were used for the electronic structure calculations. Initially, the geometry of each complex was optimized at the HF/6-31G $(d, p)$ level of theory. Later, all geometry optimizations were carried out at the MP2 level of theory using the $6-31 \mathrm{G}(d, p)$ basis set. Frequency calculations were carried out to ascertain the nature of the resultant stationary point. Most of the geometries reported in this paper are characterized as minima with real frequencies. The remaining structures have very small or negligible imaginary frequencies. Basis set superposition error (BSSE) corrections ${ }^{29}$ have been made for all the $\Delta E$ values reported.

\section{Results and discussion}

\subsection{Mono-coordinated Complexes}

Table 1 lists the $\Delta E$ values obtained for alkali and alkaline-earth metal cations and $\mathrm{Al}^{3+}$ with one water molecule: The $\Delta E$ values for $\mathrm{Na}^{+}, \mathrm{K}^{+}, \mathrm{Mg}^{2+}, \mathrm{Ca}^{2+}$ and $\mathrm{Al}^{3+}$ with one water molecule come out to be -26.1 , $-18.6,-81.9,-54.2$ and $-193.2 \mathrm{kcal}^{\mathrm{mol}}{ }^{-1}$, respectively. The $\Delta E$ values for a benzene molecule with $\mathrm{Na}^{+}$, $\mathrm{K}^{+}, \mathrm{Mg}^{2+}, \mathrm{Ca}^{2+}$ and $\mathrm{Al}^{3+}$ are $-23.5,-15.9,-112.2$, -65.4 and $-345.8 \mathrm{kcal} . \mathrm{mol}^{-1}$, respectively. For both benzene and water, the $\Delta E$ values follow the trend of charge density values. That is, $\Delta E$ increases with an increase in the charge density (listed in Table 1) of the cation. Incidentally, values reported in Table 1 are comparable in magnitude to the values reported by others, wherever available.

The $\Delta E$ values are much larger for the dications than for the monocations. From the results listed in Table 1, it is clear that $\mathrm{Na}^{+}$and $\mathrm{K}^{+}$favour interaction with water over benzene by 2.6 and $2.7 \mathrm{kcal}^{\mathrm{mol}}{ }^{-1}$, respectively. 
Table 1. Interaction energy $(\Delta E)$ values (BSSE corrected) in kcal.mol ${ }^{-1}$ units for different cations with water $(W)$ and benzene $(B)$ and $\pi$-thickness $(\rho)$ values for benzene at the MP2 level of theory using the 6-31G $(d, p)$ basis set. All distances are in $\AA$. Charge density $(\varepsilon)$ values are given in $\times 10^{10} \mathrm{C} / \mathrm{m}^{3}$ units.

\begin{tabular}{|c|c|c|c|c|c|c|c|}
\hline$M^{q+}$ & $\varepsilon$ & $\Delta E\left(M^{q+} W\right)$ & $\Delta E\left(M^{q+} B\right)$ & $r^{33,34}$ & $R$ & $\rho$ & $R\left(M^{q+}-\mathrm{O}\right)$ \\
\hline $\mathbf{N a}^{+}$ & 4.4 & $\begin{array}{l}-26.1 \\
-23.1^{23} \\
-24.0^{27}\end{array}$ & $\begin{array}{l}-23.5 \\
-21.3^{23} \\
-21.3^{27}\end{array}$ & 0.95 & 2.42 & 1.47 & 2.23 \\
\hline $\mathbf{K}^{+}$ & 1.6 & $\begin{array}{l}-18.6 \\
-17.8^{23}\end{array}$ & $\begin{array}{l}-15.9 \\
-17.0^{23}\end{array}$ & 1.33 & 2.87 & 1.54 & 2.62 \\
\hline $\mathbf{M g}^{2+}$ & 27.8 & $\begin{array}{l}-81.9 \\
-76.2^{23}\end{array}$ & $\begin{array}{l}-112.2 \\
-108.8^{23} \\
-108.9^{27}\end{array}$ & 0.65 & 1.98 & 1.33 & 1.95 \\
\hline $\mathbf{C a}^{2+}$ & 7.8 & $\begin{array}{l}-54.2 \\
-53.5^{23}\end{array}$ & $\begin{array}{l}-65.4 \\
-72.8^{23}\end{array}$ & 0.99 & 2.50 & 1.51 & 2.33 \\
\hline $\mathbf{A l}^{3+}$ & 77.0 & -193.2 & -345.8 & 0.53 & 1.64 & 1.11 & 1.77 \\
\hline
\end{tabular}

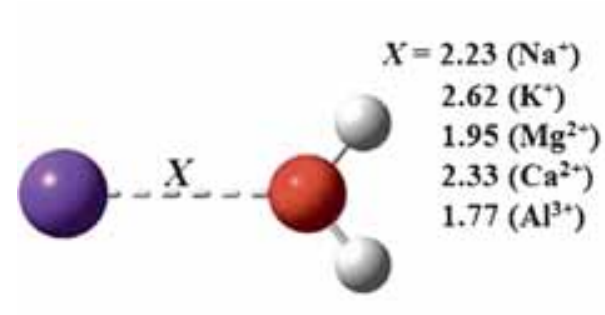

(a) $\mathrm{M}^{q^{+}-W}$

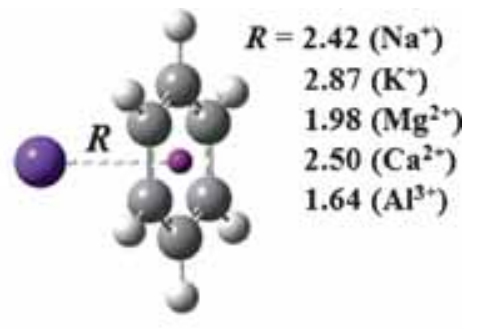

(b) $\mathrm{M}^{q^{+}-\mathrm{B}}$

Figure 1. Optimized geometry of (a) $M^{q+} W$ and (b) $M^{q+} B$ complexes. All distances are in $\AA$ units.

Therefore, benzene cannot displace water in $M^{+}-\mathrm{OH}_{2}$ complexes when $M^{+}=\mathrm{Na}^{+}$or $\mathrm{K}^{+}$. This is in contrast to what was observed experimentally by Sunner et al., ${ }^{30}$ They found that the $\mathrm{K}^{+}-B$ interaction was stronger than that of $\mathrm{K}^{+}-\mathrm{OH}_{2}$ in gas phase, although $\mathrm{Mg}^{2+}$ and $\mathrm{Ca}^{2+}$ interact more favourably with benzene over water by 30.3 and $11.2 \mathrm{kcal}^{\mathrm{mol}}{ }^{-1}$, respectively. Therefore, benzene can displace a water molecule from $M^{2+}-\mathrm{OH}_{2}$ complexes, when $\mathrm{M}^{2+}=\mathrm{Mg}^{2+}, \mathrm{Ca}^{2+}$. The trication $\mathrm{Al}^{3+}$ also prefers to interact strongly with benzene over water by $152.6 \mathrm{kcal}^{\mathrm{mol}}{ }^{-1}$.

Optimized geometries of the adduct of water and benzene molecules with various cations are shown schematically in Figure 1. All the geometries reported have been found to be minima with real frequencies. Some important features like the $\pi$-cloud thickness values applicable in the case of benzene as a partner and $M^{q+}-\mathrm{O}$ distances applicable in the case of water as the ligand are listed in Table 1 . The $\mathrm{M}^{q+}-\mathrm{O}$ distance increases with an increase in the size of the cation. In the case of $\mathrm{M}^{q+}-B$ complexes, all cations in the optimized geometry are placed symmetrically along the $\mathrm{C}_{6^{-}}$ axis of the benzene ring. The values of $R$ and $\rho$ reported for $\mathrm{Na}^{+}, \mathrm{K}^{+}, \mathrm{Mg}^{2+}, \mathrm{Ca}^{2+}$ and $\mathrm{Al}^{3+}$ for $M^{q+} B$ complexes in Table 1 show clearly that $R$ increases with an increase in $r$. In the case of $\mathrm{Al}^{3+}$, the distance of the cation from the benzene centroid $(1.64 \AA)$ is less than that from the $\mathrm{O}$ atom $(1.77 \AA)$ of water. Clearly, cations with a higher charge density interact more strongly with the $\pi$-system.

\subsection{Di-coordinated Complexes}

Values of $\Delta E$ for $\mathrm{Na}^{+}, \mathrm{K}^{+}, \mathrm{Mg}^{2+}, \mathrm{Ca}^{2+}$ and $\mathrm{Al}^{3+}$ interacting with two water molecules are computed to be $-48.2,-35.1,-155.3,-103.7$ and $-358.2 \mathrm{kcal}^{\mathrm{mol}}{ }^{-1}$, respectively. The $\Delta E$ values for different cations with two benzene molecules in a sandwich geometry are listed in Table 2 as $-42.8\left(\mathrm{Na}^{+}\right),-30.3\left(\mathrm{~K}^{+}\right),-189.3$ $\left(\mathrm{Mg}^{2+}\right),-119.4\left(\mathrm{Ca}^{2+}\right)$ and $-519.5\left(\mathrm{Al}^{3+}\right) \mathrm{kcal}^{\mathrm{mol}}{ }^{-1}$. $\Delta E$ values for different cations di-coordinated with benzene molecules are found to be approximately two times that for the corresponding mono-coordinated cation-benzene complexes, suggesting that the interaction energy values are additive for $\pi-$ cation $-\pi$ interaction. For $M^{q+} B W$, the $\Delta E$ values are found to be $-45.9\left(\mathrm{Na}^{+}\right),-32.5\left(\mathrm{~K}^{+}\right),-176.2\left(\mathrm{Mg}^{2+}\right),-112.0$ $\left(\mathrm{Ca}^{2+}\right)$ and $-466.1\left(\mathrm{Al}^{3+}\right) \mathrm{kcal}^{\mathrm{mol}}{ }^{-1}$. 
Table 2. Interaction energy $(\Delta E)$ values (BSSE corrected) in $\mathrm{kcal} \cdot \mathrm{mol}^{-1}$ units for di- and tri-coordinated of different cations with benzene and water at the MP2 level of theory using the $6-31 \mathrm{G}(d, p)$ basis set. 'NC' in the table stands for 'not converged'.

\begin{tabular}{|c|c|c|c|c|c|c|c|}
\hline$M^{q+}$ & $\Delta E\left(M^{q+} W_{2}\right)$ & $\Delta E\left(M^{q+} B_{1} W_{1}\right)$ & $\Delta E\left(M^{q+} B_{2}\right)$ & $\Delta E\left(M^{q+} W_{3}\right)$ & $\Delta E\left(M^{q+} B_{1} W_{2}\right)$ & $\Delta E\left(M^{q+} B_{2} W_{1}\right)$ & $\Delta E\left(M^{q+} B_{3}\right)$ \\
\hline $\mathrm{Na}^{+}$ & -48.2 & -45.9 & $\begin{array}{l}-42.8 \\
-43.4^{26} \\
-38.7^{27}\end{array}$ & -68.3 & -63.6 & -58.7 & $\begin{array}{l}\mathrm{NC} \\
-53.7^{26}\end{array}$ \\
\hline $\mathrm{K}^{+}$ & -35.1 & -32.5 & $\begin{array}{l}-30.3 \\
-30.7^{26}\end{array}$ & -49.7 & -46.6 & -44.5 & -42.9 \\
\hline $\mathrm{Mg}^{2+}$ & -155.3 & -176.2 & $\begin{array}{l}-189.3 \\
-191.3^{26} \\
-185.7^{27}\end{array}$ & -215.4 & -222.8 & -218.4 & $\mathrm{NC}$ \\
\hline $\mathrm{Ca}^{2+}$ & -103.7 & -112.0 & $\begin{array}{l}-119.4 \\
-122.8^{26}\end{array}$ & -147.8 & -152.2 & -154.4 & $\begin{array}{l}-152.2 \\
-154.5^{26}\end{array}$ \\
\hline $\mathrm{Al}^{3+}$ & -358.2 & -466.1 & -519.5 & -484.2 & -528.6 & -565.3 & $\mathrm{NC}$ \\
\hline
\end{tabular}

For all the cases investigated, the $\Delta E$ value increases with an increase in the charge density of the cation. As a result, the interaction energy is maximum for $\mathrm{Al}^{3+}$. The $\Delta E$ values for di-coordinated complexes involving divalent cations are much larger than those for monovalent cations. This can be attributed to the higher charge density of the alkaline-earth metal cations than that for the alkali-metal cations. For all the di-coordinated complexes, the $\Delta E$ values were found to be nearly the sum of the $\Delta E$ values for the corresponding monocoordinated complexes of different cations. However, the deviation from additivity is significantly large for $\mathrm{Mg}^{2+}$ and $\mathrm{Al}^{3+}$.

As in the case of mono-coordinated $\mathrm{M}^{q+} \mathrm{B}$ and $M^{q+} W$ complexes, the interaction energy of $\mathrm{Na}^{+}$and $\mathrm{K}^{+}$ions with two molecules of water is larger than that for two molecules of benzene by 5.4 and $4.8 \mathrm{kcal}^{\mathrm{mol}}{ }^{-1}$, respectively. In contrast, the interaction energy for $\mathrm{Mg}^{2+}, \mathrm{Ca}^{2+}$ and $\mathrm{Al}^{3+}$ ions is larger for two benzene molecules than for two molecules of water by 34.0, 15.7 and $161.3 \mathrm{kcal}_{\mathrm{mol}} \mathrm{m}^{-1}$, respectively. Thus, the alkaline earth metal ions have a stronger binding with two benzene molecules than with two water molecules. The $\Delta E$ values for the $M^{q+} B_{1} W_{1}$ complexes lie in between the $\Delta E$ values for $M^{q+} W_{2}$ and $M^{q+} B_{2}$, but the order is different for the alkali metal cations and the alkaline earth metal cations and $\mathrm{Al}^{3+}$ ion. In the case of alkali cations, $\Delta E$ values follow the order: $M^{+} B_{2}<M^{+} B_{1} W_{1}<$ $M^{+} W_{2}$. However, in the case of alkaline-earth-metal cations and $\mathrm{Al}^{3+}$ ion, the $\Delta E$ values follow the reverse order: $M^{2+} W_{2}<M^{2+} B_{1} W_{1}<M^{2+} B_{2}$.

Optimized geometries of $M^{q+} B_{2}, M^{q+} B_{1} W_{1}$ and $M^{q+} W_{2}$ complexes are illustrated in Figure 2. Values of $R, r$ and $\rho$ for $M^{q+}-B_{2}$ and $M^{q+}-B_{1} W_{1}$ complexes

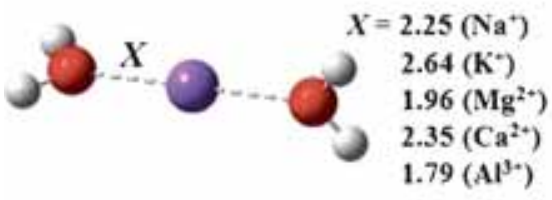

(a) $\mathrm{M}^{q^{+}}-\mathrm{W}_{2}$

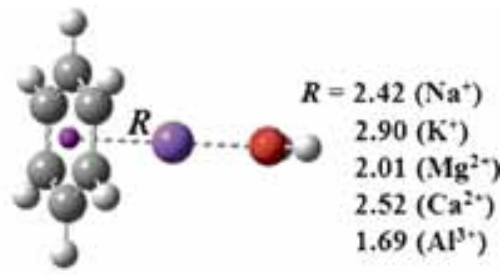

(b) $M^{q^{+}}-B_{I} W_{I}$

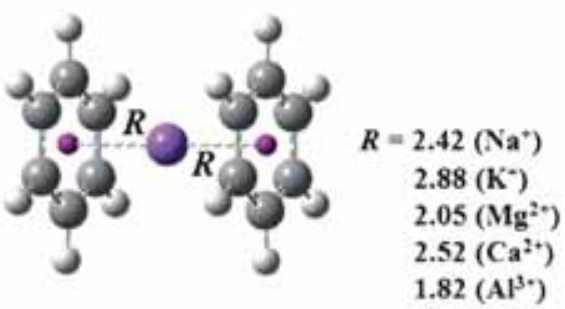

(c) $\mathrm{M}^{+}-\mathrm{B}_{2}$

Figure 2. Optimized geometry of (a) $M^{q+} W_{2}$, (b) $M^{q+} B_{1} W_{1}$, and (c) $M^{q+} B_{2}$ complexes. All distances are in $\AA$ units. 
Table 3. Values of $R$ and $\rho$ for different complexes of $\mathrm{Na}^{+}, \mathrm{K}^{+}, \mathrm{Mg}^{2+}, \mathrm{Ca}^{2+}$ and $\mathrm{Al}^{3+}$ as obtained from ab initio calculations at the MP2 level of theory using the $6-31 \mathrm{G}(d, p)$ basis set. All distances are in $\AA$.

\begin{tabular}{lccccc}
\hline$M^{q+}$ & $\mathrm{Na}^{+}$ & $\mathrm{K}^{+}$ & $\mathrm{Mg}^{2+}$ & $\mathrm{Ca}^{2+}$ & $\mathrm{Al}^{3+}$ \\
\hline$r^{33,34}$ & 0.95 & 1.33 & 0.65 & 0.99 & 0.53 \\
$R\left(M^{q+} B_{1} W_{1}\right)$ & 2.42 & 2.90 & 2.01 & 2.52 & 1.69 \\
$\rho\left(M^{q+} B_{1} W_{1}\right)$ & 1.47 & 1.57 & 1.36 & 1.53 & 1.16 \\
$R\left(M^{q+} B_{2}\right)$ & 2.42 & 2.88 & 2.05 & 2.52 & 1.82 \\
$\rho\left(M^{q+} B_{2}\right)$ & 1.47 & 1.55 & 1.40 & 1.53 & 1.29 \\
$R\left(M^{q+} B_{1} W_{2}\right)$ & 2.50 & 2.92 & 2.09 & 2.55 & 1.79 \\
$\rho\left(M^{q+} B_{1} W_{2}\right)$ & 1.55 & 1.59 & 1.44 & 1.56 & 1.26 \\
$R\left(M^{q+} B_{2} W_{1}\right)$ & 2.54 & 2.91 & NA & 2.57 & NA \\
$\rho\left(M^{q+} B_{2} W_{1}\right)$ & 1.59 & 1.58 & NA & 1.58 & NA \\
$R\left(M^{q+} B_{3}\right)$ & NA & 2.91 & NA & 2.65 & NA \\
$\rho\left(M^{q+} B_{3}\right)$ & NA & 1.58 & NA & 1.66 & NA \\
\hline
\end{tabular}

are listed in Table 3. A post-optimization frequency analysis indicates that most of the geometries are minima with real frequencies and some have first or second order saddle points with small and negligible imaginary frequencies as shown in Table $\mathrm{S} 1$.

It is found that the $R$ values for $M^{q+} B_{2}$ are slightly enhanced, when compared to those for $M^{q+} B$, which can be attributed to the steric adjustment of two benzene moieties around the cation. In the optimized geometry of $M^{q+} B_{2}$, the two benzene molecules are on opposite sides of the metal and are eclipsed with respect to each other. In $M^{q+} B_{1} W_{1}$ complexes, the $M^{q+}-B$ and $M^{q+}-\mathrm{O}$ bond lengths are nearly the same as in the case of $M^{q+} B_{2}$ and $M^{q+} W_{2}$. The value of the $B(X)-M^{q+}-$ $\mathrm{O}$ bond angle varies in the range $170-180^{\circ}$ for different cations. For $\mathrm{Mg}^{2+}$ and $\mathrm{Al}^{3+}$ ions, the optimized geometry is linear, but for $\mathrm{Na}^{+}, \mathrm{K}^{+}$and $\mathrm{Ca}^{2+}$ it is slightly bent $\left(\sim 170^{\circ}\right)$.

Summary: Alkali metal cations have more affinity towards water than for benzene, their $\Delta E$ values order being $M^{+} B_{2}<M^{+} B_{1} W_{1}<M^{+} W_{2}$. The $\Delta E$ values are larger for alkaline earth metal cations and $\mathrm{Al}^{3+}$ ion interacting with benzene than with water, their $\Delta E$ values order being $M^{2+} W_{2}<M^{2+} B_{1} W_{1}<M^{+} B_{2} . \Delta E$ values are the largest for $\mathrm{Al}^{3+}$. The $\Delta E$ value increases with an increase in the charge density of the cations.

\subsection{Tri-coordinated Complexes}

The $\Delta E$ values for $M^{q+} B_{m} W_{n}, m, n \geq 0, m+n=3$ are listed in Table 2. The $\Delta E$ values for $\mathrm{K}^{+}$and $\mathrm{Ca}^{2+}$ interacting with three molecules of benzene are -42.9 and $-152.2 \mathrm{kcal}^{\mathrm{mol}}{ }^{-1}$, respectively. Efforts to optimize the geometry for $M^{q+} B_{3}$ for $M^{q+}=\mathrm{Na}^{+}$, $\mathrm{Mg}^{2+}$ and $\mathrm{Al}^{3+}$ were not successful. In the case of $M^{q+} B_{2} W_{1}$, the $\Delta E$ values for $\mathrm{Na}^{+}, \mathrm{K}^{+}, \mathrm{Mg}^{2+}, \mathrm{Ca}^{2+}$ and

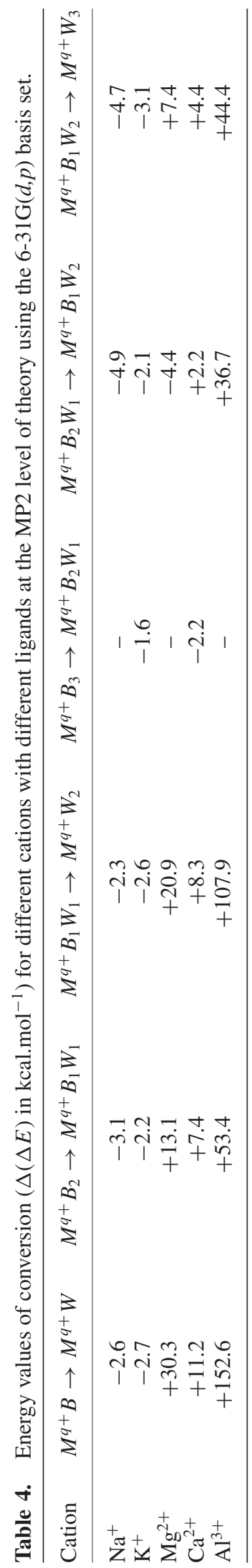


$\mathrm{Al}^{3+}$ are found to be $-58.7,-44.5,-218.4,-154.4$ and $-565.3 \mathrm{kcal}^{\mathrm{mol}}{ }^{-1}$, respectively. The $\Delta E$ values for $M^{q+} B_{1} W_{2}$ with $\mathrm{Na}^{+}, \mathrm{K}^{+}, \mathrm{Mg}^{2+}, \mathrm{Ca}^{2+}$ and $\mathrm{Al}^{3+}$ are $-63.6,-46.6,-222.8,-152.2$ and $-528.6 \mathrm{kcal}^{\mathrm{mol}}{ }^{-1}$, respectively and are comparable to those for $M^{q+} B_{2} W_{1}$. Values of $\Delta E$ for $\mathrm{Na}^{+}, \mathrm{K}^{+}, \mathrm{Mg}^{2+}, \mathrm{Ca}^{2+}$ and $\mathrm{Al}^{3+}$ in $M^{q+} W_{3}$ complex are computed to be $-68.3,-49.7$, $-215.4,-147.8$ and $-484.2 \mathrm{kcal}^{\mathrm{mol}} \mathrm{l}^{-1}$, respectively.

For tri-coordinated complexes, it can be concluded that the alkali metal cations $\left(\mathrm{Na}^{+}\right.$and $\left.\mathrm{K}^{+}\right)$have a larger affinity towards water than to benzene. The $\Delta E$ value increases when benzene moiety is replaced sequentially by water in the cation-benzene trimer $\left(M^{q+} B_{3}\right)$ complex as can be seen in the values listed in Table 4 . Hydration $M^{+} B_{3} \longrightarrow M^{+} B_{2} W_{1}$ is favoured for $\mathrm{K}^{+}$ by $1.6 \mathrm{kcal} \cdot \mathrm{mol}^{-1}$. Further replacement of benzene by water $\left\{M^{+} B_{2} W_{1} \longrightarrow M^{+} B_{1} W_{2}\right\}$ is favoured by 4.9 and $2.1 \mathrm{kcal}^{\mathrm{mol}}{ }^{-1}$ for $\mathrm{Na}^{+}$and $\mathrm{K}^{+}$, respectively. Further hydration $M^{+} B_{1} W_{2} \longrightarrow M^{+} W_{3}$ is also favoured by -4.7 and $-3.1 \mathrm{kcal}^{\mathrm{mol}}{ }^{-1}$ for $\mathrm{Na}^{+}$and $\mathrm{K}^{+}$, respectively.

The trend in $\Delta E$ values for ligation is different for alkaline-earth metal cations. In the case of tricoordinated complexes, our results show that alkaline earth metal cations favor partial dehydration. For $M^{2+} W_{3} \longrightarrow M^{2+} B_{1} W_{2}$ conversion, the conversion energy values are -7.4 and $-4.4 \mathrm{kcal}^{\mathrm{mol}}{ }^{-1}$, for
$\mathrm{Mg}^{2+}$ and $\mathrm{Ca}^{2+}$, respectively. Further replacement of water by benzene $\left\{M^{2+} B_{1} W_{2} \longrightarrow M^{2+} B_{2} W_{1}\right\}$, is disfavoured for $\mathrm{Mg}^{2+}$ by $4.4 \mathrm{kcal} . \mathrm{mol}^{-1}$ and favoured for $\mathrm{Ca}^{2+}$ by $2.2 \mathrm{kcal}^{\mathrm{mol}}{ }^{-1}$, respectively. For the process $\mathrm{Ca}^{2+} B_{2} W_{1} \longrightarrow \mathrm{Ca}^{2+} B_{3}$, the conversion energy is $+2.2 \mathrm{kcal}^{\mathrm{mol}}{ }^{-1}$ i.e., the conversion is energetically not favourable. Thus, the most stable trimer complex with $\mathrm{Mg}^{2+}$ is $\mathrm{Mg}^{2+} B_{1} W_{2}$ and for $\mathrm{Ca}^{2+}$, it is $\mathrm{Ca}^{2+} B_{2} W_{1}$. The trication $\mathrm{Al}^{3+}$ favours binding with benzene over water. The first and second replacement of water molecules from water trimer by benzene is favoured by -44.4 and $-36.7 \mathrm{kcal} . \mathrm{mol}^{-1}$, respectively for $\mathrm{Al}^{3+}$.

In the case of $M^{q+} B_{3}$, the $\Delta E$ values for different cations are close to three times the value for corresponding $M^{q+} B$ complex. However, the deviation from additivity $\left(4.8 \mathrm{kcal}^{\mathrm{mol}}{ }^{-1}\right.$ for $\left.\mathrm{K}^{+}\right)$is larger for the trimer than for the dimer $\left(6.2\right.$ and $1.5 \mathrm{kcal} . \mathrm{mol}^{-1}$ for $\mathrm{Na}^{+}$and $\mathrm{K}^{+}$, respectively). The $\Delta E$ value for $\mathrm{Ca}^{2+}-B_{3}$ deviates from additivity much more $\left(44.0 \mathrm{kcal} . \mathrm{mol}^{-1}\right)$ suggesting that the deviation is larger for cations having a higher charge density.

Geometries of all tri-coordinated complexes have been optimized at the MP2 level of theory with the $6-31 \mathrm{G}(d, p)$ basis set. A frequency analysis for the optimized geometries shows that all the optimized geometries of $M^{q+} B_{3}$ and $M^{q+} W_{3}$ studied are minima with

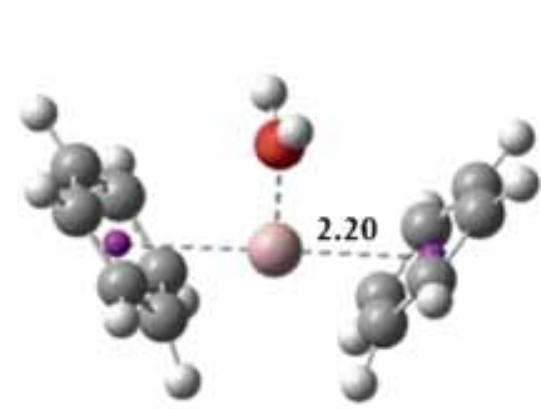

(a) $\mathrm{Al}^{3+}-\mathrm{B}_{2} \mathrm{~W}_{1}$

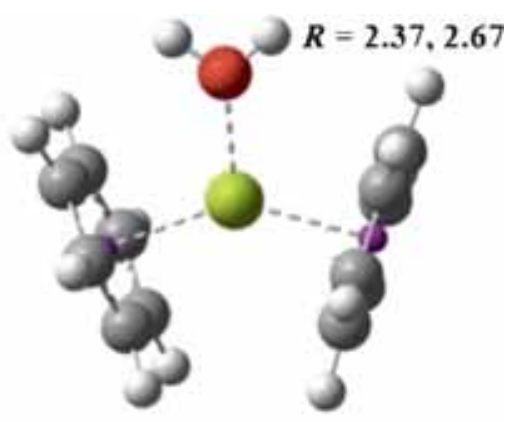

(b) $\mathrm{Mg}^{2+}-\mathrm{B}_{2} \mathrm{~W}_{1}$

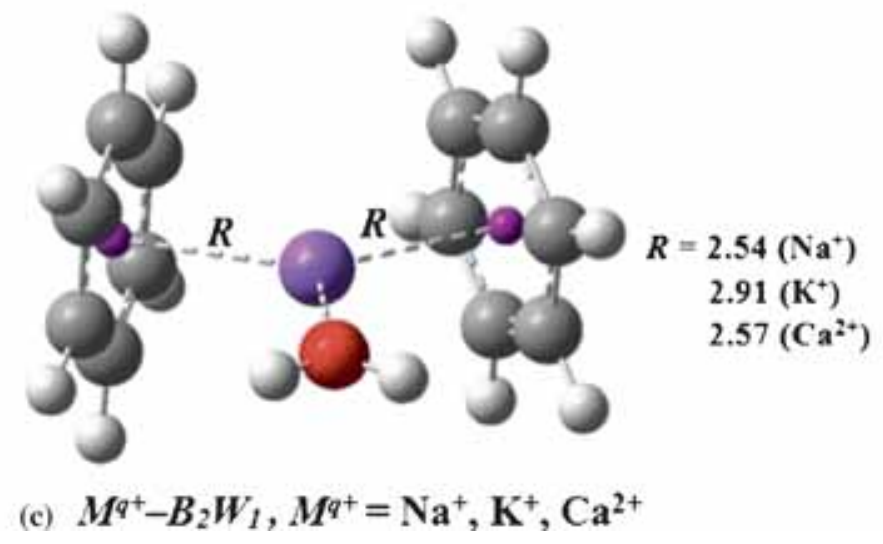

Figure 3. Optimized geometry of $M^{q+} B_{2} W_{1}$ complexes. All distances are in $\AA$ units. 
all real frequencies. The optimized geometries for the cations tri-coordinated with benzene are shown in Figure 4(c). All the three benzene rings are equidistant from the central cation arranged in a trigonal planar fashion thus forming a cavity of three benzene rings with the cation encapsulated in it. The cationcentroid distance and the $\pi$-thickness values for $\mathrm{M}^{q+} B_{3}$ for $\mathrm{Na}^{+}, \mathrm{K}^{+}$and $\mathrm{Ca}^{2+}$ are listed in Table 3. The angles between the benzene centres measured from the cation come out to be $\sim 120^{\circ}$. Nearby $\mathrm{H}$ atoms of benzene rings avoid each other by changing the angles to minimize repulsion. The optimized geometry of $\mathrm{M}^{q+} W_{3}$ is also included in Figure 4. The angles between water molecules measured from the cation come out to be $\sim 120^{\circ}$. The $\mathrm{H}$ atoms in water molecules are suitably tilted to minimize repulsion. It should be noted that

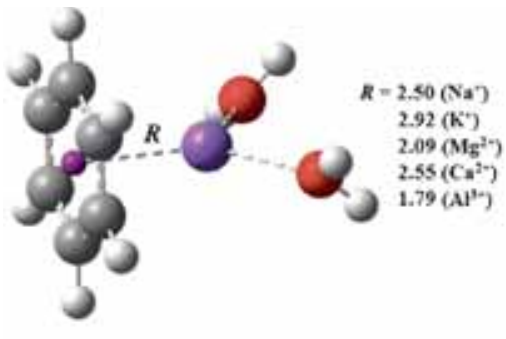

(a) $\mathrm{M}^{*}-\mathrm{B}_{3} \mathrm{~W}_{2}$

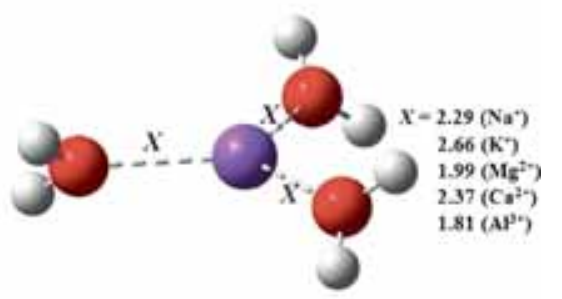

(b) $M \mathrm{~F}^{*}-\mathrm{W}_{\text {, }}$

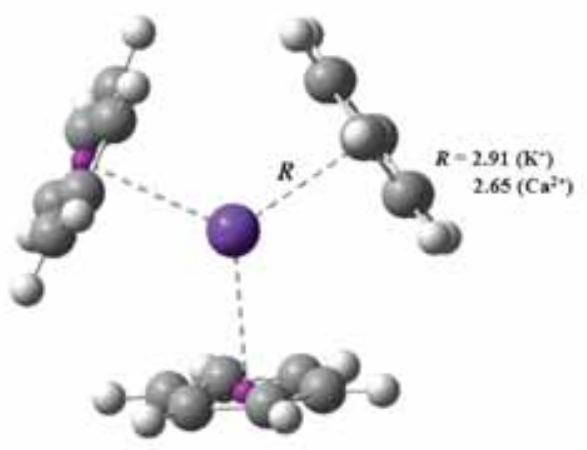

(c) $\mathrm{MN}^{*}-\mathrm{B}_{1}, \mathrm{M}^{*}=\mathrm{K}^{*}, \mathrm{Ca}^{2}$

Figure 4. Optimized geometry of (a) $M^{q+} B_{1} W_{2}$, (b) $M^{q+} W_{3}$ and (c) $M^{q+} B_{3}$ complexes. All distances are in $\AA$ units.

Table 5. Values of $\Delta E$ (BSSE corrected) in $\mathrm{kcal}^{\mathrm{mol}}{ }^{-1}$ units for different cations with different ligands at the MP2 level of theory using the $6-31 \mathrm{G}(d, p)$ basis set. For $\mathrm{K}^{+} B_{4}$, however, the results were obtained at the HF level of theory using the 6-31G $(d, p)$ basis set.

\begin{tabular}{lccccc}
\hline $\mathrm{M}^{q+}$ & $\Delta E\left(M^{q+} \mathrm{B}_{4}\right)$ & $\Delta E\left(M^{q+} \mathrm{B}_{3} \mathrm{~W}_{1}\right)$ & $\Delta E\left(M^{q+} \mathrm{B}_{2} \mathrm{~W}_{2}\right)$ & $\Delta E\left(M^{q+} \mathrm{B}_{1} \mathrm{~W}_{3}\right)$ & $\Delta E\left(M^{q+} \mathrm{W}_{4}\right)$ \\
\hline $\mathbf{N a}^{+}$ & $\mathrm{NA}$ & -65.2 & -71.3 & -75.8 & -83.6 \\
$\mathbf{K}^{+}$ & 1946 & -54.1 & -56.4 & -59.0 & -62.2 \\
$\mathbf{M g}^{2+}$ & $\mathrm{NA}$ & $\mathrm{NA}$ & -251.7 & -260.6 & -264.2 \\
$\mathbf{C a}^{2+}$ & $\mathrm{NA}$ & -178.8 & -185.4 & -187.5 & -186.8 \\
$\mathbf{A l}^{3+}$ & $\mathrm{NA}$ & $\mathrm{NA}$ & -621.2 & -603.9 & -581.8 \\
\hline
\end{tabular}

Table 6. Energy values of conversion $\left(\Delta(\Delta E)\right.$ in kcal.mol $\left.{ }^{-1}\right)$ of different $M^{q+} B_{m} W_{n}$ complexes at the MP2 level of theory using the $6-31 \mathrm{G}(d, p)$ basis set.

\begin{tabular}{lccc}
\hline$M^{q+}$ & $M^{q+} B_{3} W_{1} \rightarrow M^{q+} B_{2} W_{2}$ & $M^{q+} B_{2} W_{2} \rightarrow M^{q+} B_{1} W_{3}$ & $M^{q+} B_{1} W_{3} \rightarrow M^{q+} W_{4}$ \\
\hline $\mathrm{Na}^{+}$ & -6.1 & -4.5 & -7.8 \\
$\mathrm{~K}^{+}$ & -2.3 & -2.6 & -3.2 \\
$\mathrm{Mg}^{2+}$ & $\mathrm{NA}$ & -8.9 & -3.6 \\
$\mathrm{Ca}^{2+}$ & -6.6 & -2.1 & +0.7 \\
$\mathrm{Al}^{3+}$ & $\mathrm{NA}$ & +17.3 & +22.1 \\
\hline
\end{tabular}


the smallest metal cation-centroid distance has been used to calculate the $\pi$-cloud thickness value when two benzene molecules are located at slightly different distances from the cation.

In the case of $M^{q+} B_{2} W_{1}$ complexes, the optimized geometries reported correspond to minima with real frequencies. The metal-centroid distances for $B_{2} W_{1}$ with $\mathrm{Na}^{+}, \mathrm{K}^{+}$and $\mathrm{Ca}^{2+}$ are computed to be $2.54,2.91$ and $2.57 \AA$, respectively. Distances of different carbon atoms of benzene molecules from $\mathrm{Al}^{3+}$ ion vary in the range 2.14-3.50 $\AA$. Benzene molecules are also slightly tilted in the case of $\mathrm{Mg}^{2+}$, with the $\mathrm{Mg}^{2+}-\mathrm{C}$ distance varying in the range 2.56-2.66 $\AA$ (see

Table 7. Metal-Centroid distance $(R)$ and $\pi$-thickness $(\rho)$ values for various $M^{q+} B_{m} W_{n}$ complexes obtained at the MP2 level of theory using the $6-31 \mathrm{G}(d, p)$ basis set. All distances are in $\AA$.

\begin{tabular}{lccccc}
\hline$M^{q+}$ & $\mathrm{Na}^{+}$ & $\mathrm{K}^{+}$ & $\mathrm{Mg}^{2+}$ & $\mathrm{Ca}^{2+}$ & $\mathrm{Al}^{3+}$ \\
\hline $\mathrm{r}^{33,34}$ & 0.95 & 1.33 & 0.65 & 0.99 & 0.53 \\
$R\left(M^{q+} B_{1} W_{3}\right)$ & 2.49 & 2.95 & 2.19 & 2.59 & 1.90 \\
$\rho\left(M^{q+} B_{1} W_{3}\right)$ & 1.54 & 1.62 & 1.54 & 1.60 & 1.37 \\
$R\left(M^{q+} B_{2} W_{2}\right)$ & 2.63 & 2.95 & NA & 2.62 & NA \\
$\rho\left(M^{q+} B_{2} W_{2}\right)$ & 1.68 & 1.62 & NA & 1.63 & NA \\
$R\left(M^{q+} B_{3} W_{1}\right)$ & 2.77 & 2.96 & NA & 2.72 & NA \\
$\rho\left(M^{q+} B_{3} W_{1}\right)$ & 1.82 & 1.63 & NA & 1.73 & NA \\
$R\left(M^{q+} B_{4}\right)$ & NA & 3.34 & NA & NA & NA \\
$\rho\left(M^{q+} B_{4}\right)$ & NA & 2.01 & NA & NA & NA \\
\hline
\end{tabular}

Figure 3). In all other cases $\left(\mathrm{Na}^{+}, \mathrm{K}^{+}, \mathrm{Ca}^{2+}\right)$, the $\mathrm{M}^{q+}-$ $\mathrm{C}$ distance remains nearly the same [maximum variation $\sim 0.04 \AA]$ (see Figure 3 ). The $\pi$-cloud thickness values for $B_{2} W_{1}$ interacting with $\mathrm{Na}^{+}, \mathrm{K}^{+}$, and $\mathrm{Ca}^{2+}$ are calculated to be $1.59,1.58$ and $1.58 \AA$, respectively. For the $M^{q+} B_{1} W_{2}$ complexes, all the optimized geometries reported in Figure 4 are found to be first-order saddle points with small and negligible imaginary frequency values except for $\mathrm{Mg}^{2+}$ and $\mathrm{Al}^{3+}$ (see Table $\mathrm{S} 1$ ).

\subsection{Tetra-coordinated Complexes}

The $\Delta E$ values for $M^{q+} B_{m} W_{n}, m, n \geq 0, m+$ $n=4$ for various cations are listed in Table 5. The $\Delta E$ value for $\mathrm{K}^{+}$tetra-coordinated with four benzene molecules $\left(\mathrm{K}^{+} B_{4}\right)$ at the HF level of theory with the 6$31 \mathrm{G}(d, p)$ basis set was found to be $+1946 \mathrm{kcal}^{\mathrm{mol}}{ }^{-1}$. Attempts to optimize the geometries of other tetracoordinated cation-benzene complexes were not successful. The $\Delta E$ values for the $M^{q+} B_{3} W_{1}$ with $M^{q+}=$ $\mathrm{Na}^{+}, \mathrm{K}^{+}$and $\mathrm{Ca}^{2+}$ were computed to be $-65.2,-54.1$ and $-178.8 \mathrm{kcal} . \mathrm{mol}^{-1}$, respectively. Attempts to optimize the geometry of $M^{q+} B_{3} W_{1}$ with $M^{q+}=\mathrm{Mg}^{2+}$ and $\mathrm{Al}^{3+}$ were not successful. The $\Delta E$ values for $M^{q+} B_{2} W_{2}$ with $M^{q+}=\mathrm{Na}^{+}, \mathrm{K}^{+}, \mathrm{Mg}^{2+}, \mathrm{Ca}^{2+}$ and $\mathrm{Al}^{3+}$ were found to be $-71.3,-56.4,-251.7,-185.4$ and $-621.2 \mathrm{kcal} . \mathrm{mol}^{-1}$, respectively. The $\Delta E$ values for $M^{q+} B_{1} W_{3}$ with $M^{q+}=\mathrm{Na}^{+}, \mathrm{K}^{+}, \mathrm{Mg}^{2+}$, $\mathrm{Ca}^{2+}$ and $\mathrm{Al}^{3+}$ are $-75.8,-59.0,-260.6,-187.5$

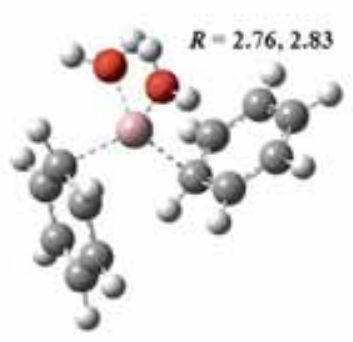

(a) $\mathrm{Al}^{3+}-\mathrm{B}_{2} \mathrm{~W}_{2}$

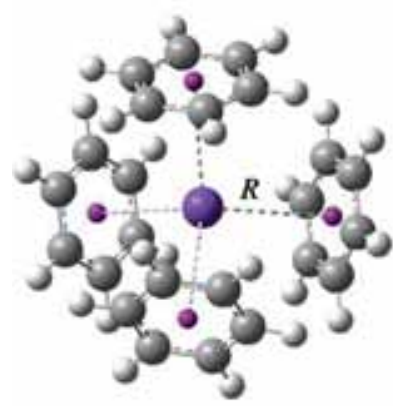

(d) $\mathrm{K}^{*}-B_{4}, R=3.34$

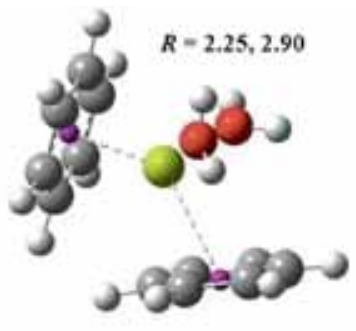

(b) $\mathrm{Mg}^{2+}-\mathrm{B}_{2} \mathrm{~W}_{2}$

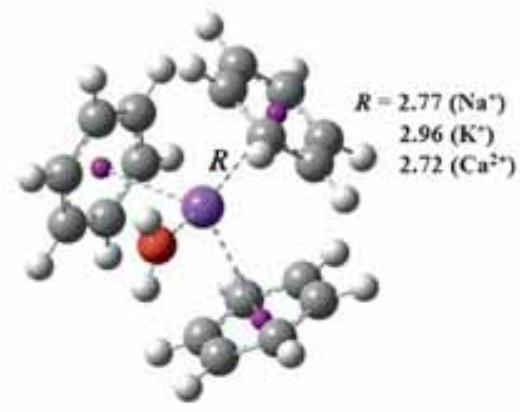

(e) $\mathrm{Mr}^{+}-\mathrm{B}_{3} \mathrm{~W}_{l}, \mathrm{Mv}^{*}=\mathrm{Na}^{*}, \mathrm{~K}^{+}, \mathrm{Ca}^{2 *}$

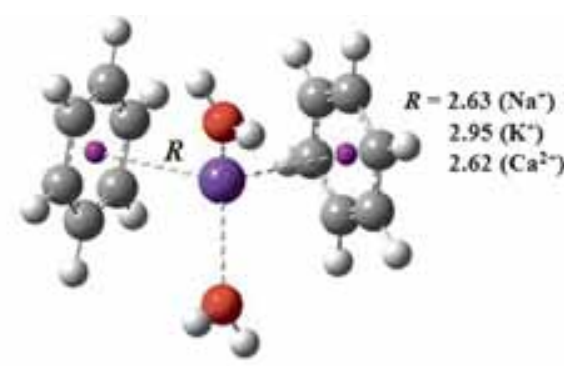

(c) $\mathrm{M}^{+}-\mathrm{B}_{2} \mathrm{~W}_{2}, \mathrm{M}^{+}=\mathrm{Na}^{+}, \mathrm{K}^{+}, \mathrm{Ca}^{2+}$

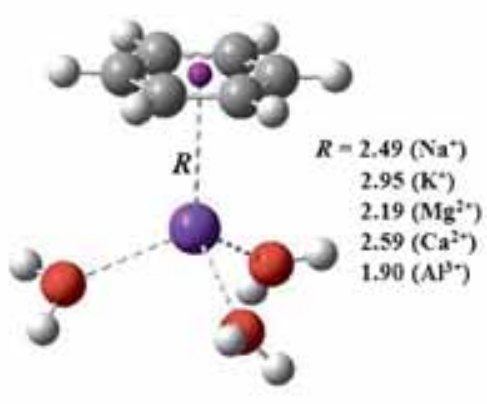

(f) $\mathrm{M}^{+}-\mathrm{B}_{1} \mathrm{~W}_{3}$

Figure 5. Optimized geometry of $M^{q+} B_{2} W_{2}, M^{q+} B_{4}$, and $M^{q+} B_{1} W_{3}$ complexes. All distances are in $\AA$ units. 
and $-603.9 \mathrm{kcal} . \mathrm{mol}^{-1}$, respectively. The $\Delta E$ values for $M^{q+} W_{4}$ with $M^{q+}=\mathrm{Na}^{+}, \mathrm{K}^{+}, \mathrm{Mg}^{2+}$, $\mathrm{Ca}^{2+}$ and $\mathrm{Al}^{3+}$ are $-83.6,-62.2,-264.2,-186.8$ and $-581.8 \mathrm{kcal}^{\mathrm{mol}}{ }^{-1}$, respectively.

In the case of tetra-coordinated complexes, it was found that the alkali metal cations $\left(\mathrm{Na}^{+}\right.$and $\left.\mathrm{K}^{+}\right)$have a larger affinity towards water than to benzene molecules. The $\Delta E$ value increases when a benzene molecule is replaced sequentially by water in the cation-benzene tetramer complex as can be seen from the values listed in Table 6. The conversion of $M^{+} B_{3} W_{1}$ to $M^{+} B_{2} W_{2}$ is favoured by -6.1 and $-2.3 \mathrm{kcal} . \mathrm{mol}^{-1}$ for $\mathrm{Na}^{+}$and

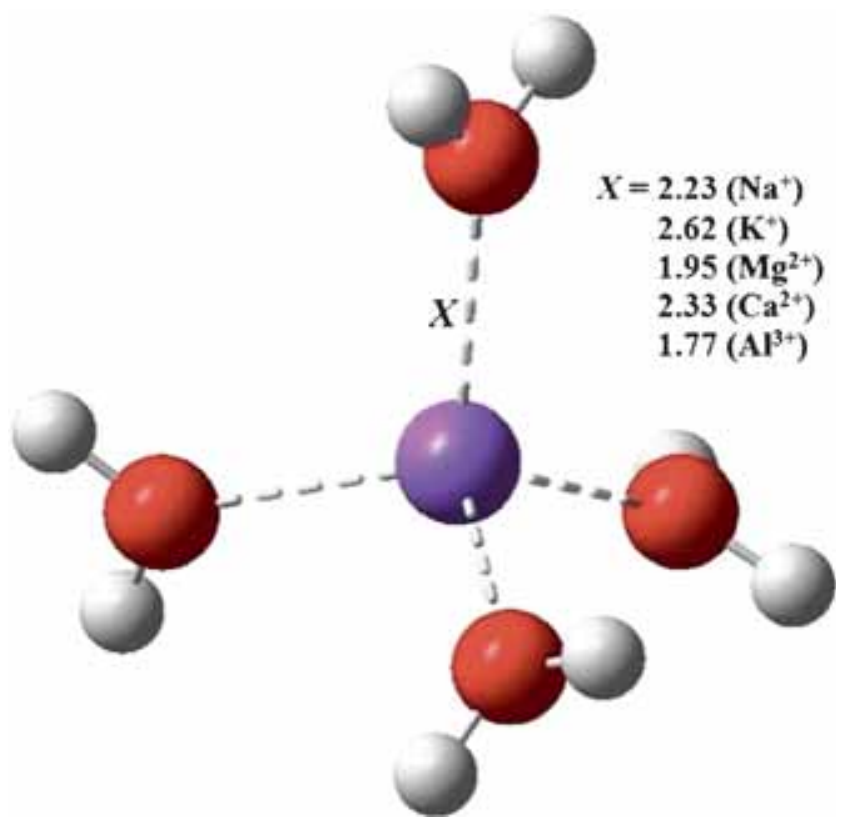

Figure 6. Optimized geometry of $M^{q+} W_{4}$ complexes. All distances are in $\AA$ units.
$\mathrm{K}^{+}$, respectively. Further replacement of benzene by water in $\left\{M^{+} B_{2} W_{2} \longrightarrow M^{+} B_{1} W_{3}\right\}$ is favoured by -4.5 and $-2.6 \mathrm{kcal}^{\mathrm{mol}}{ }^{-1}$ for $\mathrm{Na}^{+}$and $\mathrm{K}^{+}$, respectively. Further hydration $\left\{M^{+} B_{1} W_{3} \longrightarrow M^{+} W_{4}\right\}$ is favoured by -7.8 and $-3.2 \mathrm{kcal}^{-\mathrm{mol}^{-1}}$ for $\mathrm{Na}^{+}$and $\mathrm{K}^{+}$, respectively.

The trend is not so clear for the tetracoordinated complexes of the dications. While the replacement of one water molecule in $\mathrm{Mg}^{2+} W_{4}$ by benzene is energetically not favourable, partial dehydration is energetically favoured in $\mathrm{Ca}^{2+} W_{4}$. For $M^{2+} W_{4} \longrightarrow$ $M^{2+} B_{1} W_{3}$ conversion, the conversion energy values are +3.6 and $-0.7 \mathrm{kcal} \mathrm{mol}^{-1}$, for $\mathrm{Mg}^{2+}$ and $\mathrm{Ca}^{2+}$, respectively. Further replacement of water by benzene, $M^{2+} B_{1} W_{3} \longrightarrow M^{2+} B_{2} W_{2}$ is disfavoured for $\mathrm{Mg}^{2+}$ and $\mathrm{Ca}^{2+}$ by 8.9 and $2.1 \mathrm{kcal} \mathrm{mol}^{-1}$, respectively. The conversion $\mathrm{Ca}^{2+} B_{2} W_{2} \longrightarrow \mathrm{Ca}^{2+} B_{3} W_{1}$ is disfavoured by $6.6 \mathrm{kcal} \mathrm{mol}^{-1}$. The trication $\mathrm{Al}^{3+}$ shows a clear preference for binding with benzene over water. The first and second replacement of water molecule by benzene from $\mathrm{Al}^{3+} W_{4}$ are favoured by 22.1 and $17.3 \mathrm{kcal} \mathrm{mol}^{-1}$, respectively.

Values of $R$ and $\rho$ for different tetracoordinated complexes with various cations are listed in Table 7 . Optimized geometries are shown in Figure 5 and 6.

\section{Conclusion}

$A b$ initio calculations were carried to study the effect of hydration on cation- $\pi$ interaction between different alkali metal and alkaline earth metal cations and $\mathrm{Al}^{3+}$ and benzene at the MP2 level of theory using the 6-31G $(d, p)$ basis set.

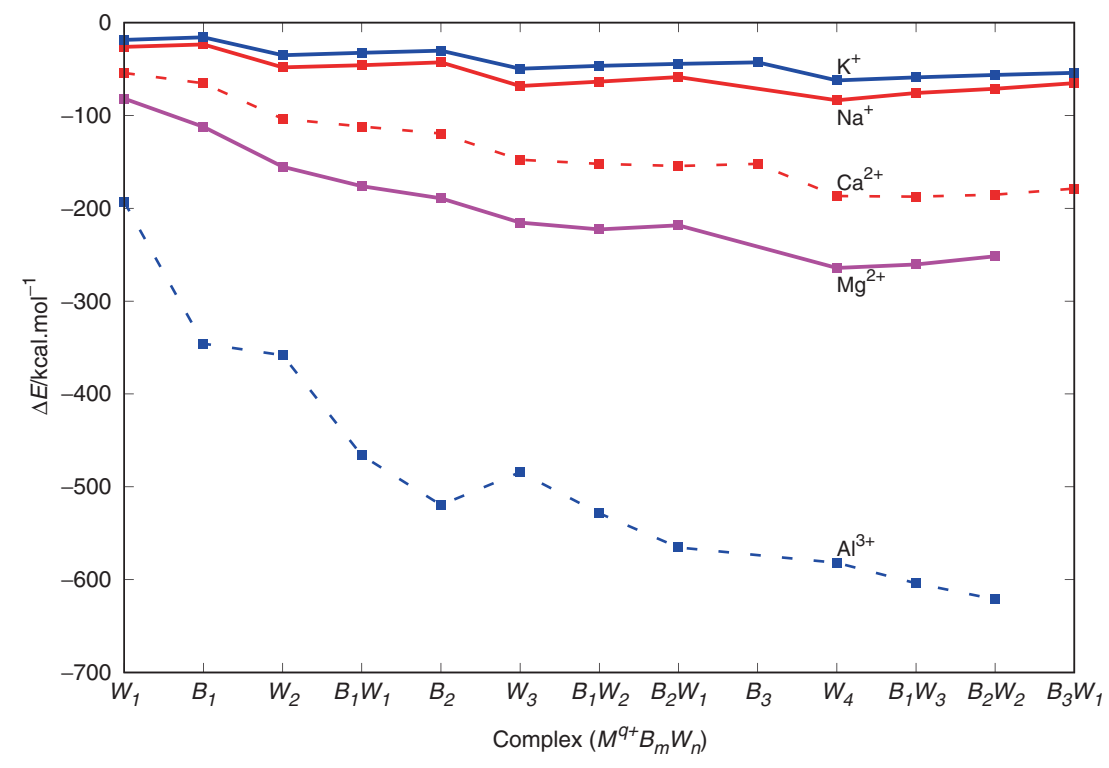

Figure 7. BSSE-corrected interaction $(\Delta E)$ energy values for various complexes plotted for different cations. 
A summary of the BSSE corrected $\Delta E$ values for all the complexes under investigation is given in Figure 7. The following conclusions could be arrived at:

1. Alkali metal cations prefer to bind with water over benzene, while alkaline-earth metal cations and $\mathrm{Al}^{3+}$ ion prefer to bind with benzene.

2. In the case of $M^{q+} B_{2}, M^{q+} B_{1} W_{1}$ and $M^{q+} W_{2}$ complexes, $\Delta E$ values follow the trend $B_{2}<$ $B_{1} W_{1}<W_{2}$ for $\mathrm{Na}^{+}$and $\mathrm{K}^{+}$, and $W_{2}<B_{1} W_{1}<$ $B_{2}$ for $\mathrm{Mg}^{2+}, \mathrm{Ca}^{2+}$ and $\mathrm{Al}^{3+}$ ions.

3. In the case of tri-coordinated complexes, $\Delta E$ values follow the trend $B_{3}<B_{2} W_{1}<B_{1} W_{2}<$ $W_{3}$, for $\mathrm{Na}^{+}$and $\mathrm{K}^{+}$and $W_{3}<B_{1} W_{2}<B_{2} W_{1}<$ $B_{3}$ for $\mathrm{Al}^{3+}$ ion. The $\mathrm{Mg}^{2+}$ and $\mathrm{Ca}^{2+}$ ions favour partial dehydration.

4. In the case of tetra-coordinated complexes, $\Delta E$ values follow the trend $B_{3} W_{1}<B_{2} W_{2}<B_{1} W_{3}<$ $W_{4}$, for $\mathrm{Na}^{+}$and $\mathrm{K}^{+}$and $W_{4}<B_{1} W_{3}<B_{2} W_{2}<$ $B_{3} W_{1}$ for $\mathrm{Al}^{3+}$. The $\mathrm{Mg}^{2+}$ and $\mathrm{Ca}^{2+}$ ions favour partial dehydration.

5. The $\Delta E$ values for all the systems under investigation vary in the following order: $\mathrm{K}^{+}<\mathrm{Na}^{+}<$ $\mathrm{Ca}^{2+}<\mathrm{Mg}^{2+}<\mathrm{Al}^{3+}$, which is the order of the metal ion charge density.

6 . The $\pi$-thickness value for benzene varies in the range 1.16-2.01 $\AA$.

7. The $\Delta E$ values for the di-coordinated and the tri-coordinated complexes are found to be nearly two/three times that for the monomer. Deviations from additivity are larger for cations having higher charge densities and as the number of $B / W$ molecules increases. The issue of cooperativity and anti-cooperativity between different noncovalent interactions has been discussed in detail by Sastry and coworkers. ${ }^{31,32}$

\section{Supplementary information}

List of imaginary frequencies for different $M^{q+} B_{m} W_{n}$ complexes can be found in the supplementary information. Supplementary Information is available at www. ias.ac.in/chemsci.

\section{Acknowledgements}

VD thanks the Department of Science and Technology, Govt. of India for an INSPIRE fellowship and IISER Mohali for the computing facility. NS is an honorary professor in Jawaharlal Nehru Centre for Advanced Scientific Research, Bangalore. He thanks the Department of Science and Technology, New Delhi for a J C Bose National Fellowship.

\section{References}

1. Desiraju G R 2002 Acc. Chem. Res. 35565

2. Steiner T 2002 Angew. Chem. Int. Ed. 4148

3. Meyer E A, Castellano R K and Diederich F 2003 Angew. Chem. Int. Ed. 421210

4. Salonen L M, Ellermann M and Diederich F 2011 Angew. Chem. Int. Ed. 504808

5. Joseph J and Jemmis E D 2007 J. Am. Chem. Soc. 129 4620

6. Parthasarathi R, Subramanian V and Sathyamurthy N 2006 J. Phys. Chem. A 1103349

7. Ma J C and Dougherty D A 1997 Chem. Rev. 971303

8. Dougherty D A 2013 Acc. Chem. Res. 46885

9. Mahadevi A S and Sastry G N 2013 Chem. Rev. 113 2100

10. Dougherty D 1996 Science 271163

11. Gallivan J P and Dougherty D 1999 Proc. Natl. Acad. Sci. U.S.A. 969459

12. Kumpf R and Dougherty D 1993 Science 2611708

13. Zhu W L, Tan X J and Puah C M 2000 J. Phys. Chem. A 1049573

14. Tan X J, Jiang H L and Zhu W L 1999 J. Chem. Soc., Perkin Trans. 1107

15. Gokel G W, De Wall S L and Meadows E S 2000 Eur. J. Org. Chem. 172967

16. DeVos A M, Ultsch M and Kossiakoff A A 1992 Science 255306

17. Mitchell J B, Nandi C L and McDonald I K 1994 J. Mol. Biol. 239315

18. Lee J S, Krasnokutski S A and Yang D $2011 \mathrm{~J}$. Chem. Phys. 134024301

19. Gallivan J P and Dougherty D A $2000 \mathrm{~J}$. Am. Chem. Soc. 122870

20. Rao J S, Zipse H and Sastry G N 2009 J. Phys. Chem. B 1137225

21. Cabarcos O M, Weinheimer C J and Lisy J M 1999 J. Chem. Phys. 1102307

22. Amicangelo J C and Armentrout P B 2000 J. Phys. Chem. A 10411420

23. Reddy A S, Zipse H and Sastry G N 2007 J. Phys. Chem. $B 11111546$

24. Nicholas J B, Hay B P and Dixon D A 1999 J. Phys. Chem. A 1031394

25. Feller D, Dixon D A and Nicholas J B 2000 J. Phys. Chem. A 10411414

26. Mishra B K, Bajpai V K, Ramanathan V, Gadre S R and Sathyamurthy N 2008 Mol. Phys. 1061557

27. Kolakkandy S, Pratihar S, Aquino A J A, Wang H and Hase W L 2014 J. Phys. Chem. A 1189500

28. Frisch M J et al., Gaussian 09; Gaussian Inc.: Pittsburg, PA. For further information, see: http://www.Gaussian. com/index.htm

29. Boys S F and Bernardi R 1979 Mol. Phys. 19553

30. Sunner J, Nishizawa K and Kebarle P 1981 J. Phys. Chem. 851814

31. Saha S and Sastry G N 2015 J. Phys. Chem. B 11911121

32. Mahadevi A S and Sastry G N 2016 Chem. Rev. 116 2775

33. Gadre S R and Sen K D 1993 J. Chem. Phys. 993149

34. Wells A F 1975 In Structural Inorganic Chemistry 4th ed. (London: Clarendon Press-Oxford, Oxford University Press) p. 259 